\title{
Cable-Free Magnetic Micro-actuator Capable of Movement in a Thin Pipe
}

\author{
H. Yaguchi and S. Sasaki* \\ Tohoku Gakuin University, 1-13-1 Tagajo, Miyagi 985-8537, Japan \\ *Daito Seiki Corp., Kayakariba 145, Ohira, Kurokawa-gun, Miyagi 981-3602, Japan
}

We previously proposed a novel micro-actuator that provides propulsion using the mechanical resonance energy of a system excited by an electromagnetic force, allowing relatively high speeds. Long-distance movement proved difficult, however, because of the need for a power supply cable. In this paper, we propose a new cable-free actuator with a mechanical dc-ac micro-inverter that can move a long distance. The mechanical dc-ac inverter incorporates a double cantilever beam that switches under an electromagnetic force. The prototype actuator is capable of moving inside a very small pipe $10 \mathrm{~mm}$ in diameter. Experimental results show that the actuator can move upwards at a speed of $5.1 \mathrm{~cm} / \mathrm{s}$. This cable-free actuator has many possible applications, including small pipe inspection and maintenance.

Key words: resonance drive, within-pipe actuator, mechanical dc-ac inverter, high-speed motion, long-distance movement

\section{Introduction}

There is increasing demand for in-piping robots able to quickly find damage and remedy undesirable conditions inside pipes used in plants for chemical and biological materials, nuclear power, and other such installations. Safety issues have encouraged the growing use of such robots in recent years for a variety of duties, including not only inspections, but also maintenance and cleaning. Many papers ${ }^{1-4)}$ have addressed possible mechanisms for moving within piping.

The author has proposed ${ }^{5}$ an actuator powered by an electric cable to provide locomotion for a maintenance robot in pipes of non-magnetic materials such as vinyl chloride, copper or stainless steel. Propulsion is provided by the mechanical resonance energy of a mass-spring system suspended by elastic springs between two permanent magnets in combination with a flexible material. This actuator has proven capable of moving at high speed over a long distance. There are several potential problems in the design, however, with regard to extending the range and avoiding tangling of the cable, and thus it is clearly desirable to adopt a cable-free system. The actuator employs resonant energy for propulsion and requires an ac source to generate the resonant vibration. An ac power supply composed of an ordinary oscillator and amplifier would be too large and heavy, however, and could not be miniaturized. It should be possible to create a micro-motor which generates torque and then transforms it into linear motion through the pipe, in the same way as standard micro-actuators, but the torque produced by micro-motors is quite small and locomotion is only possible in the horizontal direction. In order to move the motor as well as the batteries and all the additional equipment comprising the robot, this propulsion scheme would therefore require a geared motor. In turn, this would require a reducer manufactured with very high precision.

This paper proposes a new type of actuator which exhibits a very high thrusting force and is capable of extension to propulsion of a robot within a pipe. The actuator contains a micro-mechanical inverter which directly transforms dc from button batteries into ac and which can be miniaturized. Switching is performed by the vibration of a double cantilever beam. This design offers simplicity and easy miniaturization. A prototype actuator was fabricated containing a mcchanical dc-ac inverter, and is able to move through a pipe of $10 \mathrm{~mm}$ inner diameter (ID). The driving characteristics and the range of the actuator were observed.

The results hold great promise for the creation of highly mobile actuators capable of moving in pipes with diameters of under $10 \mathrm{~mm}$.

\section{Cable-Free Micro-actuator for In-Piping Movement}

Figure 1 shows our proposed cable-free actuator capable of moving within a $10 \mathrm{~mm}$ ID pipe. It consists of a propulsion module (Fig. 2) and a mechanical inverter (Fig. 3). The propulsion module converts the mechanical resonance energy stimulated by the ac electrical power source into locomotive power. The inverter powers the propulsion module by converting the $\mathrm{dc}$ from the battery pack into ac at the natural frequency of the propulsion module. The propulsion module and inverter are linked through a universal-joint-style coupler, allowing the actuator to accommodate bends by articulating at its center. The fabricated actuator is $116 \mathrm{~mm}$ long, with a total mass of $16 \mathrm{~g}$ including a battery pack of 12 button batteries.

\subsection{Structure of the Propulsion Module}

As shown in Fig. 2, the power module consists of two identical permanent magnets, translational springs, and an excitation electromagnet. The permanent magnets are $\mathrm{NdFeB}$ cylinders magnetized in the axial direction. They measure $8 \mathrm{~mm}$ in diameter and $5 \mathrm{~mm}$ in height, and have a surface magnetic flux density of $450 \mathrm{mT}$. The translational springs are stainless steel compression-coil-type with an outer diameter (OD) of $7.5 \mathrm{~mm}$, a free length of $19 \mathrm{~mm}$, and a constant $k=1020 \mathrm{~N} / \mathrm{m}$. The excitation electromagnet consists of an iron core $3 \mathrm{~mm}$ in diameter with 4000 turns of $0.07 \mathrm{~mm}$ diameter copper wire.

The electrical resistance of the electromagnet is $280 \Omega$. The springs and electromagnet are placed in an aluminum tube of $8 \mathrm{~mm} \mathrm{OD}$, and $5.5 \mathrm{~mm} \mathrm{ID,}$ and the permanent magnets are glued to the ends of the spring. The between the iron and the permanent 


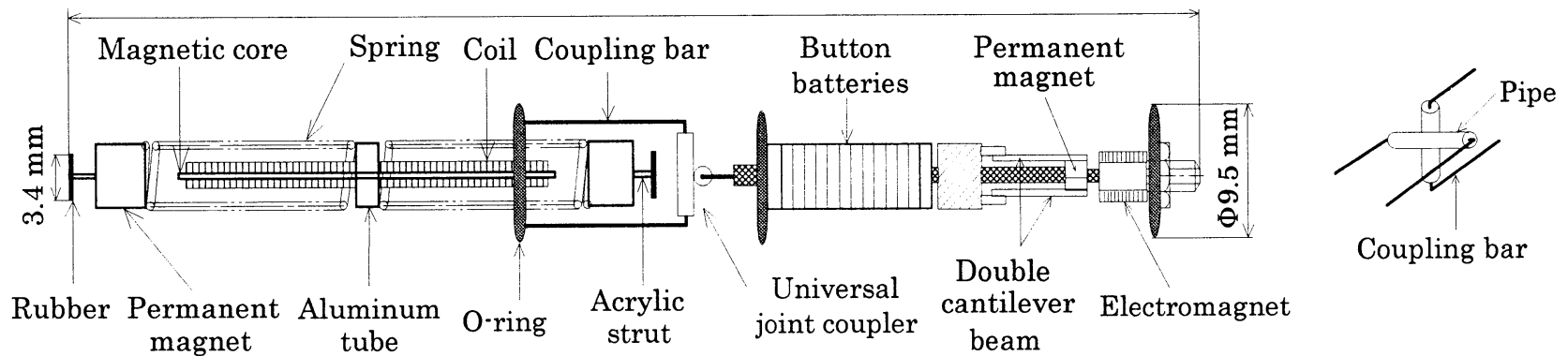

(a) Overview of structure

(b) Details of coupler

Fig. 1 Cable-free-type micro-actuator structure $(\Phi 10 \mathrm{~mm})$.
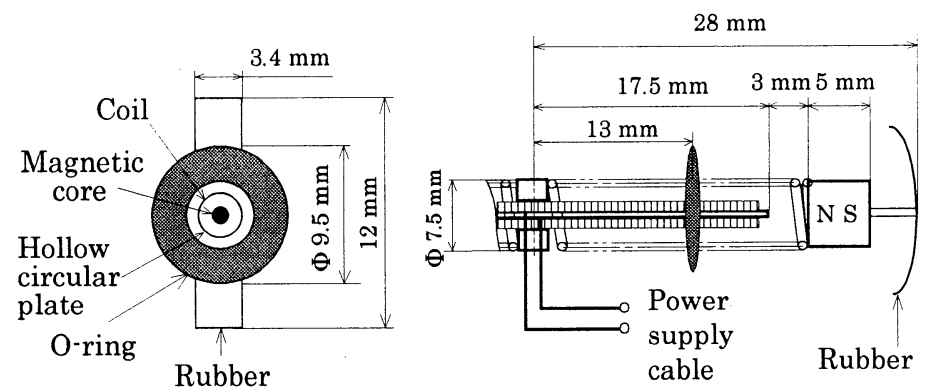

Fig. 2 Propulsion module of an actuator.

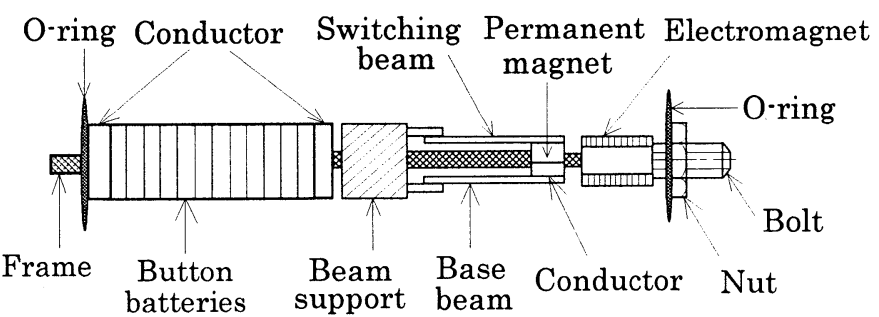

Fig. 3 DC-AC inverter of an actuator.

magnets in the static condition is $3 \mathrm{~mm}$. The leg providing the thrusting force, made of a natural rubber, is $12 \mathrm{~mm}$ long, $3.4 \mathrm{~mm}$ wide, and $0.5 \mathrm{~mm}$ thick. It is attached to one of the permanent magnets by means of acrylic struts $1 \mathrm{~mm}$ in diameter. The propulsion module is $56 \mathrm{~mm}$ long with a mass of $10 \mathrm{~g}$.

The propulsion module can be approximated as a three-degrees-of-freedom model consisting of the sum of the permanent magnet and the acrylic strut bar masses, $m$, and the electromagnet mass, $M$ (Fig. 4(a)). If the masses are treated as point masses and displacements $x_{i}(i=1,2,3)$ are measured as shown, the equations of translational motion can be written as follows:

$$
\left.\begin{array}{l}
m \ddot{x}_{1}+k\left(x_{1}-x_{2}\right)=0 \\
M \ddot{x}_{2}-k\left(x_{1}-2 x_{2}+x_{3}\right)=0 \\
m \ddot{x}_{3}-k\left(x_{2}-x_{3}\right)=0
\end{array}\right\}
$$

Here, the first term on the left side of each equation is the inertial term, and the second term represents the coupled vibration between the masses and the springs. The solution of Eq. (1) yields the eigenvibration mode and the eigenfrequency of the propulsion module. The propulsion

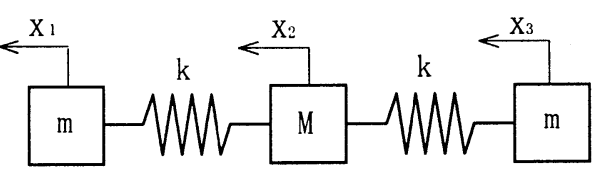

(a) Equivalent model of a micro-actuator

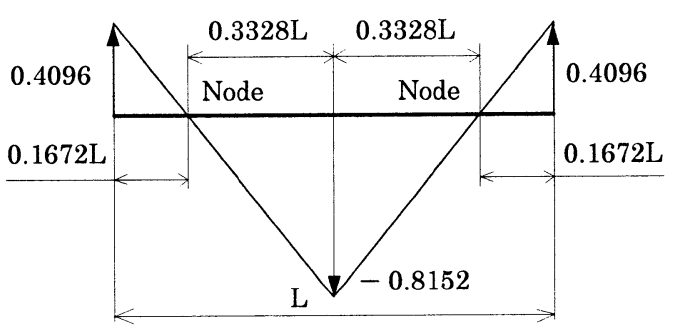

(b) Vibration mode

Fig. 4 Three-degrees-of-freedom model.

method used in this paper is the same as that reported previously ${ }^{5)}$, the third vibration mode. Here, $m=4.08 \mathrm{~g}$ and $M=4.10 \mathrm{~g}$, yielding the third eigenfrequency $f_{3}=137$ $\mathrm{Hz}$. Figure 4(b) illustrates this mode. The operating principles of the propulsion module are as described previously ${ }^{5)}$ and will be omitted here.

Before the inverter module was designed, the locomotion characteristics of the propulsion module were observed using a cable-powered model. The model was

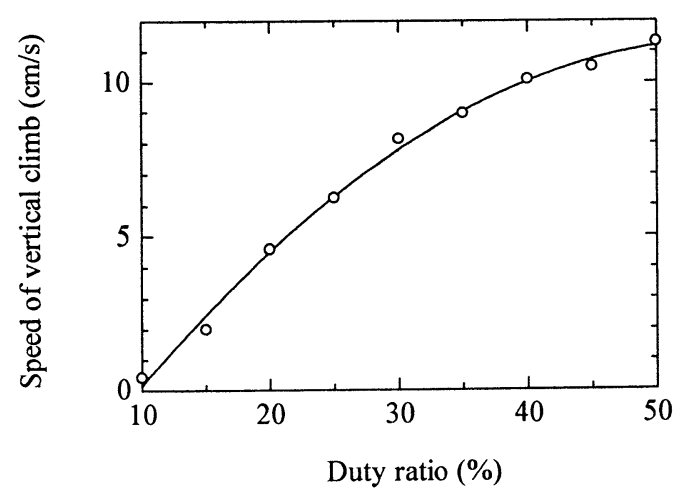

Fig. 5 Relationship between the load mass and speed of vertical climb. 
fabricated and inserted in a $10 \mathrm{~mm}$ ID acrylic pipe and the electromagnet was supplied with an amplified square wave from a signal generator driving the system at the third eigenfrequency. The actual third resonant frequency was $134 \mathrm{~Hz}$. Figure 5 presents the relation between the duty factor of the $16 \mathrm{~V}$ amplitude square wave supplied to the propulsion module and the speed of vertical climb of the propulsion module. The locomotion characteristics abruptly deteriorated when the duty factor was decreased to below $30 \%$.

\subsection{Structure and Operating Principles of the Mechanical DC-AC Inverter}

Figure 6 shows the mechanical dc-ac inverter proposed in this paper. The inverter is composed of a permanent magnet, an electromagnet, a switching system with copper plate conductors, and a double cantilever beam. This beam consists of a cantilevered base beam with a copper conductor attached only at the tip, and a cantilevered switching beam incorporating a copper conductor and a permanent magnet.

The conductors and electromagnet are connected as shown in the figure and are connected to a dc source such as a battery. The beams vibrate, bringing the conductors into contact, and then a repulsing force operates on the switching beam. As the switching beam vibrates and the conductors make and break contact, the switching system is cycled on and off, converting the dc voltage into a square alternating waveform. The switching beam uses part of the energy from the square wave to maintain its vibration.

The output voltage is limited to one polarity, either positive or negative, determined by the connection of the inverter. A further limitation is that this inverter is not capable of self-excitation from the rest condition; a starter must be used to initiate vibration of the switching beam.

\subsection{Design of the Inverter}

Before fabrication of the micro-inverter that drives the propulsion module, a test was conducted using the mechanism shown in Fig. 6. The acrylic beam material had a thickness $h=0.2 \mathrm{~mm}$, a Young's modulus $E=$

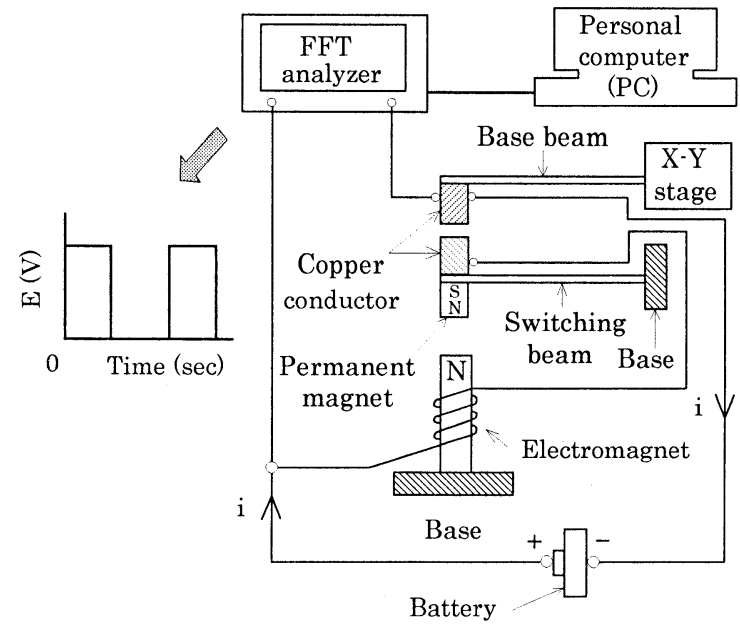

Fig. 6 Experimental apparatus.
$3.51 \times 10^{9} \mathrm{~N} / \mathrm{m}^{2}$, and a density $\rho=1103 \mathrm{~kg} / \mathrm{m}^{3}$. The $\mathrm{NdFeB}$ permanent magnet was magnetized in the axial direction and measured $1.5 \mathrm{~mm}$ in height and $5 \mathrm{~mm}$ in diameter. The excitation electromagnet was $3 \mathrm{~mm}$ in diameter and $6 \mathrm{~mm}$ in length, and was made of mild steel and wound in 200 turns of $0.1 \mathrm{~mm}$ copper wire. The dc source for the experiment was a pack of two alkaline dry cells of LR6 type. The switching beam was fabricated with a width $b=8 \mathrm{~mm}$ and a free span length $\ell=16.8$ $\mathrm{mm}$ so as to have an eigenfrequency $f_{s}=50 \mathrm{~Hz}$. The width of the base beam was $6 \mathrm{~mm}$. The base beams attached to the X-Y stage were varied to identify the length which resulted in no initial contact pressure between the conductors on the double cantilever beam. The voltage waveform generated during switching of the double cantilever beam was stored in a PC via a fast Fourier transform (FFT) analyzer.

Figure 7 shows the square voltage waves produced and the displacement of the switching beam tips for base beams with eigenfrequencies $f_{b}=45,35,25 \mathrm{~Hz}$, and $15 \mathrm{~Hz}$, obtained by varying the beam length. The figures reveal that at 45,35 , and $25 \mathrm{~Hz}$, the switching and base beams contacted each other during every period, while at $15 \mathrm{~Hz}$, the switching beam contacted the base beam during every

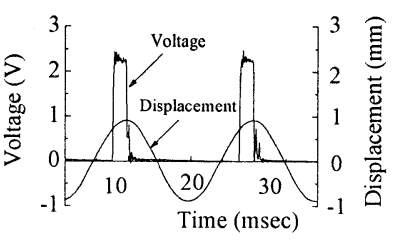

(a) $\mathrm{f}_{\mathrm{b}}=45 \mathrm{~Hz}$

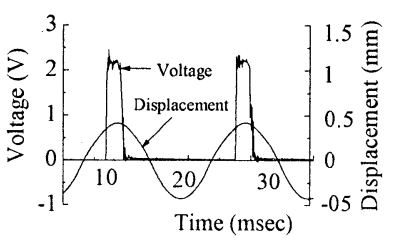

(b) $\mathrm{f}_{\mathrm{b}}=35 \mathrm{~Hz}$

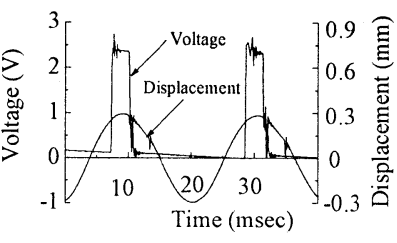

(c) $\mathrm{f}_{\mathrm{b}}=25 \mathrm{~Hz}$

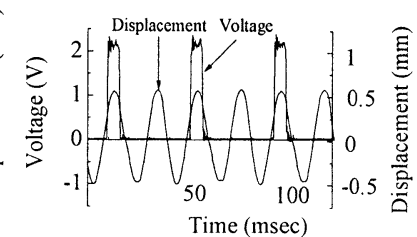

(d) $\mathrm{f}_{\mathrm{b}}=15 \mathrm{~Hz}$
Fig. 7 Displacement of the switching beam and voltage produced by the inverter.

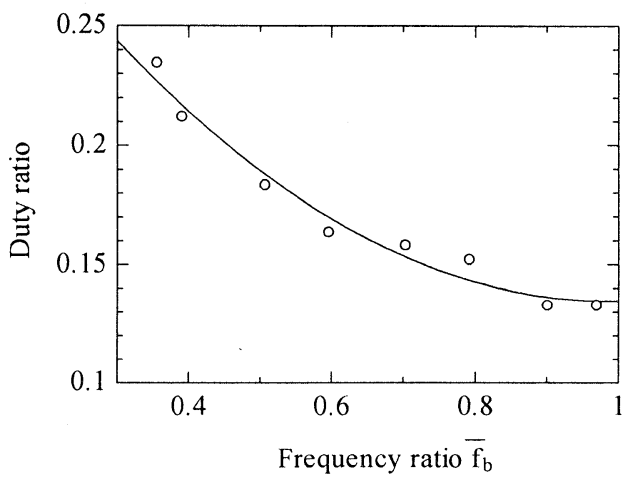

Fig. 8 Relationship between the frequency ratio and duty ratio. 


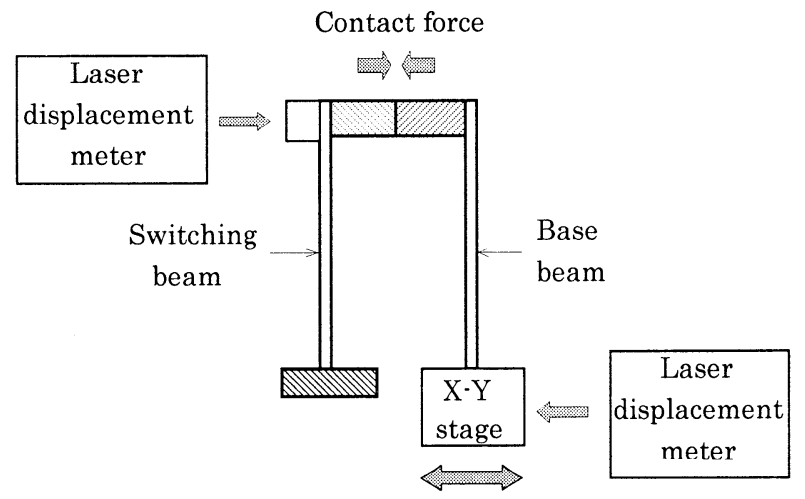

Fig. 9 Measurement of the initial contact force.

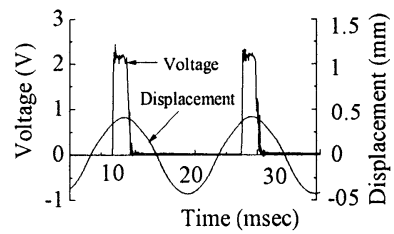

(a) $\mathrm{P}=0 \mathrm{mN}$

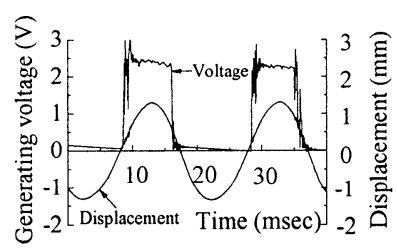

(c) $\mathrm{P}=2.73 \mathrm{mN}$

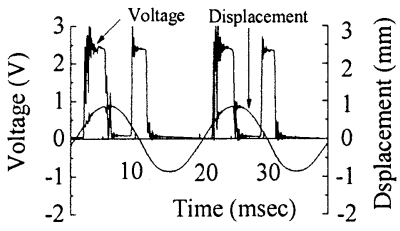

(b) $\mathrm{P}=1.64 \mathrm{mN}$

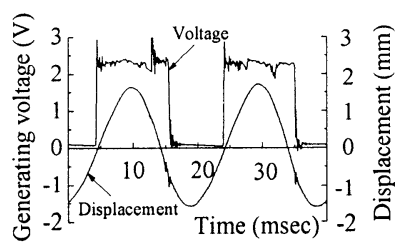

(d) $\mathrm{P}=3.82 \mathrm{mN}$
Fig. 10 Displacement of the switching beam and voltage produced by the contact force.

other period, indicating that the two beams did not vibrate together at this switching rate. The beams vibrated synchronously over the range of frequency ratios $\bar{f}_{b}\left(=f_{b}, f_{s}\right)$ of $0.36-1$. Thus, synchronous vibration was generally undisturbed by small variations in the ratio of stiffnesses between the beams.

Figure 8 presents the relation between $\bar{f}_{b}$ and the duty factor measured by using the generated voltage square waveform shown in Fig. 7. Clearly, as the eigenfrequency of the base beam approaches that of the switching beam, the duty factor of the generated voltage decreases. An $\bar{f}_{b}$ of 0.36 provided the maximum duty factor of $23 \%$. As shown in Fig. 5, the driving speed when the duty factor was $23 \%$ was about half that when the duty factor was $50 \%$.

It was anticipated that the two beams would restrict each other's vibrational displacement when there was an initial contact force between them, increasing their contact time and, in consequence, the duty factor. An experiment was conducted to measure the duty factor of the generated square wave by shifting the $\mathrm{X}-\mathrm{Y}$ stage to force the base beam against the switching beam (Fig. 9). The initial contact force $P$ can be calculated by using the following equations:

$$
\left.\begin{array}{l}
P=K_{s}\left(D_{x}-D_{s}\right) \\
K_{s}=3 E I / \ell^{3} \quad, \quad I=b h^{3} / 12
\end{array}\right\}
$$

where $D_{x}$ is the displacement of the $\mathrm{X}-\mathrm{Y}$ stage, $D_{s}$ is the displacement of the switching beam tip, and $K_{s}$ is the spring constant of the switching beam. Figure 10 shows the variations in produced voltage with initial contact force when $f_{b}$ and $f_{s}$ were held constant at $35 \mathrm{~Hz}$ and 50 $\mathrm{Hz}$, respectively, for $\bar{f}_{b}=0.7$, using the same beams as described above. The duty factor increased with initial contact force and was $57 \%$ when the contact force was $3.82 \mathrm{mN}$.

\subsection{Fabrication of an Inverter for the Propulsion Module}

The micro dc-ac inverter shown in Fig. 3 was fabricated on the basis of the described experimental results. The dimensions are provided in Fig. 11. It is composed of a copper conductor, an electromagnet, a permanent magnet, a double cantilever beam system with identical beams, an aluminum beam support, and a frame. The cylindrical $\mathrm{NdFeB}$ permanent magnet attached to the switching beam is magnetized in the axial direction, is $1 \mathrm{~mm}$ high $\times 2 \mathrm{~mm}$ in diameter, and has a surface magnetic intensity of 200 $\mathrm{mT}$. The magnet also serves as conductor. The switching beam is attached to the copper plate and its length is adjusted to match the $134 \mathrm{~Hz}$ eigenfrequency of the propulsion module. The base beam was cut to the same free span length and attached to the copper plate. It incorporates a copper conductor $2 \mathrm{~mm}$ long and $2 \mathrm{~mm}$ in diameter. The initial contact force can be adjusted by

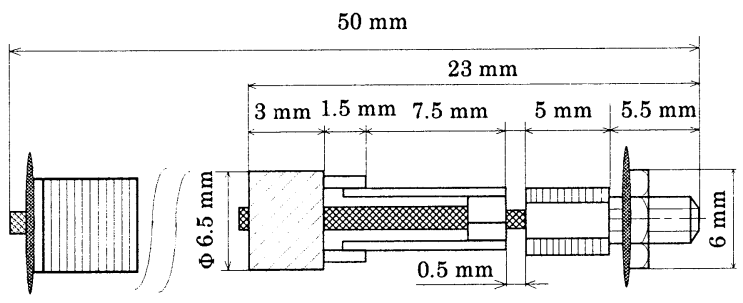

Fig. 11 Dimensions of the dc-ac inverter.

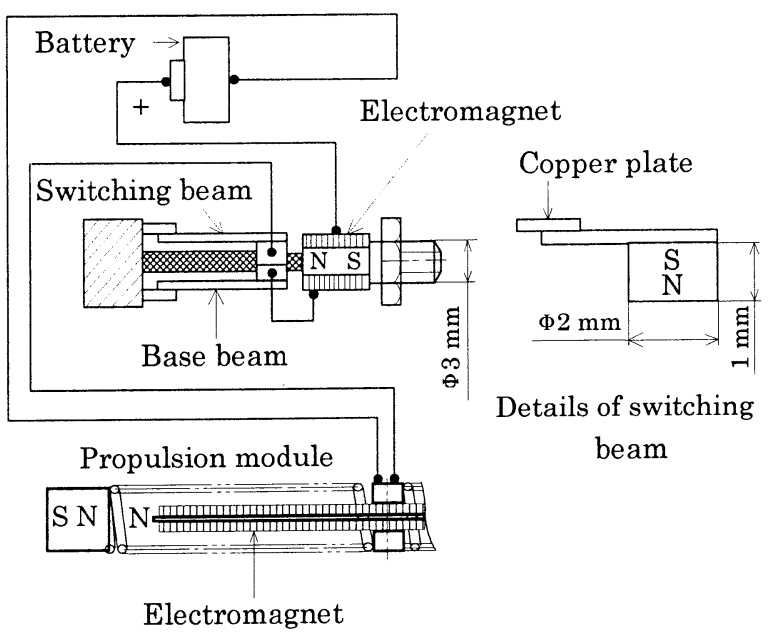

Fig. 12 Connection of the propulsion module and inverter. 


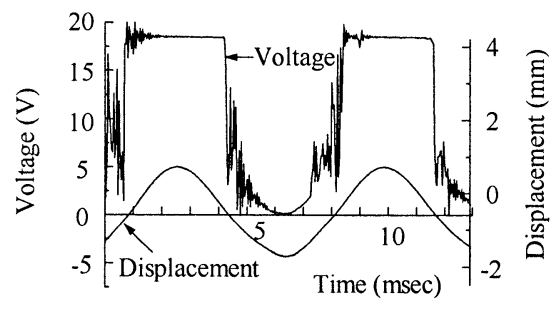

Fig. 13 Displacement of the switching beam and voltage produced by the inverter.

bending the supporting copper plate. The final dimensions for both members of the doublc cantilever bean were set to the same dimensions as the acrylic beams used in the experiment: $0.1 \mathrm{~mm}$ thick, $2.2 \mathrm{~mm}$ wide, with a free span length of $7.5 \mathrm{~mm}$. The ratio of the eigenfrequencies of the beams, $\bar{f}_{b}$, is 0.7 .

The electromagnet with a mild steel core $3 \mathrm{~mm}$ in diameter and $5 \mathrm{~mm}$ long wrapped in 600 turns of $0.09 \mathrm{~mm}$ copper wire is attached to a plastic bolt $3 \mathrm{~mm}$ in diameter. The electromagnet has a resistance of $40 \Omega$. The beam support is fixed to the frame and the bolt incorporating the electromagnet is fixed to the frame by means of a plastic nut. The gap between the permanent magnet and electromagnet was set at $0.5 \mathrm{~mm}$. The inverter module measures $6.5 \mathrm{~mm}$ in diameter and $23 \mathrm{~mm}$ in overall length, and has a mass of $1.6 \mathrm{~g}$.

The inverter module and propulsion module were coupled together as shown in Fig. 12 and were connected to an 18 VDC source. Figure 13 shows a graph of the 134 $\mathrm{Hz}$ voltage square wave produced by the inverter module when the initial contact force in the dual cantilever beam was set at $1.83 \mathrm{mN}$. The figure indicates that the duty factor of this waveform was $50 \%$.

\section{Locomotion Characteristics of the Cable-Free Actuator}

Maxell SR621W silver-oxide button batteries were used as the power source for the actuator. Each battery is 6.8 $\mathrm{mm}$ in diameter and $2.15 \mathrm{~mm}$ thick, with a mass of $0.3 \mathrm{~g}$ and a capacity of $18 \mathrm{mAh}$ at a nominal output of $1.55 \mathrm{~V}$. The battery pack was mounted on a frame, which contained the electrical contacts for the batteries. The overall length of the inverter module with 12 batteries mounted was $50 \mathrm{~mm}$ and the mass was $5.4 \mathrm{~g}$. The inverter module was coupled through a universal joint to the propulsion module, as described earlier and shown in Fig. 1. O-ring was attached to the propulsion module at the nodal point of the third vibration mode (see Fig. 2 and 4) and coupling bars were used to form the universal joint. The completely fabricated actuator was then inserted into an acrylic pipe with an ID of $10 \mathrm{~mm}$. Harmonic excitation of the switching beam at its eigenfrequency was then induced by using a coil outside the pipe in order to excite vibration of the double cantilever beam. This initiated action in the inverter, in turn initiating motion of the actuator.

Table 1 shows the speeds attained by the actuator in the
Table 1 Comparison of speed.

\begin{tabular}{|c|c|c|}
\hline Dry cells & 10 & 12 \\
\hline $\begin{array}{c}\text { down } \\
(\mathrm{cm} / \mathrm{s})\end{array}$ & 10.8 & 17.7 \\
\hline $\begin{array}{c}\text { Horizontal } \\
(\mathrm{cm} / \mathrm{s})\end{array}$ & 6.2 & 10.1 \\
\hline $\begin{array}{c}\text { Vertical } \\
(\mathrm{cm} / \mathrm{s})\end{array}$ & 3.1 & 5.1 \\
\hline
\end{tabular}

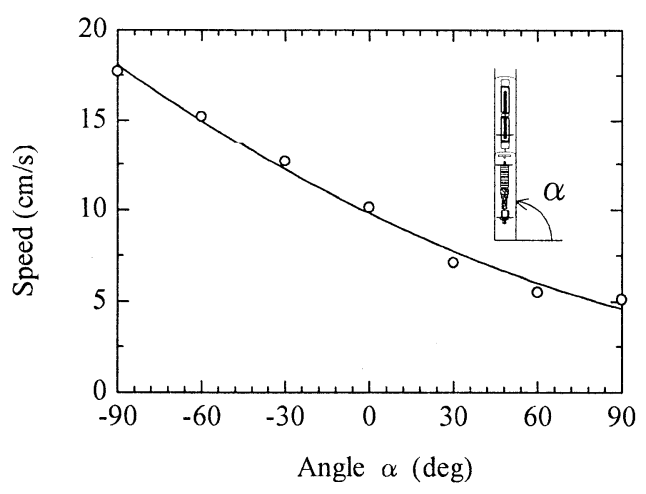

Fig. 14 Relationship between angle and speed.

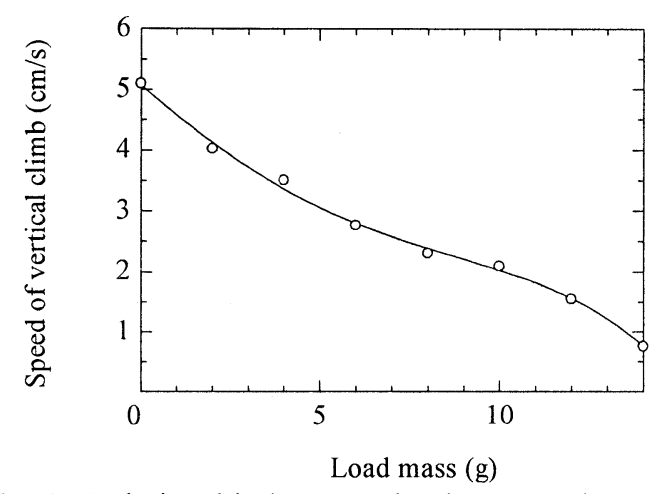

Fig. 15 Relationship between load mass and speed of vertical climb.

Table 2 Operating time and range.

\begin{tabular}{|c|c|c|}
\hline Batteries & 10 & 12 \\
\hline $\begin{array}{c}\text { Motion time } \\
\text { (min) }\end{array}$ & 34 & 28 \\
\hline $\begin{array}{c}\text { Horizontal } \\
\text { motion (m) }\end{array}$ & 143 & 170 \\
\hline $\begin{array}{c}\text { Vertical } \\
\text { motion (m) }\end{array}$ & 64 & 86 \\
\hline
\end{tabular}

downward, horizontal, and upward directions with battery packs containing either 10 or 12 batteries. With 12 batteries, the maximum vertical upward speed was 5.1 $\mathrm{cm} / \mathrm{s}$. This is quite high for a cable-free actuator. With 10 batteries, the speed was $3.1 \mathrm{~cm} / \mathrm{s}$, a sufficient speed for practical use.

Figure 14 shows the relation between the maximum speed of the actuator and the tilt angle, $\alpha$, of the pipe when a 12-battery pack is used. The angle was varied from $\alpha=$ $-90^{\circ}$ (straight downward) to $\alpha=90^{\circ}$ (straight upward). The speed decreased in a roughly linear manner with 
increasing tilt angle, $\alpha$. The speed when moving straight down was about 3.5 times that when moving straight up. This indicates that the mass of the actuator was a factor, suggesting that further size and mass reduction of the actuator are desirable. Figure 15 shows the relation between load mass and speed when moving straight upward using a 12-battery pack. The figure indicates that the actuator could climb at $2.3 \mathrm{~cm} / \mathrm{s}$ when pulling a $10 \mathrm{~g}$ load mass, a moderately high performance. Since the propulsion module of this actuator is directly connected in series with the electromagnets, the electric power supplied by 12 button batteries is about $1.08 \mathrm{~W}$ (input voltage 18.6 $\mathrm{V}$, current $0.058 \mathrm{~A}$ ). The results in Fig. 15 indicate an actuator output power of $0.008 \mathrm{~W}$, an efficiency of only $0.74 \%$. Still, in comparison to the cable-powered actuator described in previous research ${ }^{5)}$, which had a power efficiency of about $1.2 \%$, there is not a serious drop in efficiency for this battery-powered version. The main reason for the low efficiency is probably the transformation loss of energy due to rubber leg through which the resonance energy is transformed into locomotive power. A high loss is probably not unique to this actuator but inevitable in any actuator for which the propulsion relies on highly frictional pressure applied by an elastic material.

Table 2 shows the maximum operating time with 10 or 12 batteries. The difference in operating times was ascribed to the greater occurrence of high-frequency transients and the resulting higher voltage amplitude at the higher generated square voltage waveform. The operating time for a 12-battery pack was $28 \mathrm{~min}$, providing a total operating range (one-way) of $170 \mathrm{~m}$ for horizontal travel or $86 \mathrm{~m}$ for vertical travel. The operating time was the actual time the actuator could be operated continuously after insertion into the pipe. The operating range was determined by multiplying the measured speed shown in Table 1 by the measured operating time.

\section{Conclusion}

A cable-free actuator powered by a micro dc-ac inverter and capable of moving within a pipe was proposed and tested. When powered by a 12-battery pack of button batteries, the actuator displayed speeds of 17.7 $\mathrm{cm} / \mathrm{s}$ moving straight downward, $10.1 \mathrm{~cm} / \mathrm{s}$ moving horizontally, and $5.1 \mathrm{~cm} / \mathrm{s}$ moving straight upward. The actuator was found to be fully applicable to inspection of pipe interiors. Since it moves downward much more quickly than it climbs, the actuator must be lightened to eliminate this large disparity.

The total operating range of this actuator is $170 \mathrm{~m}$ in the horizontal direction or $86 \mathrm{~m}$ in the vertical direction over an operating time of $28 \mathrm{~min}$ when powered by a 12-battery pack. If the power requirement of the propulsion module can be lowered and the generation of high-frequency harmonics of square voltage waves suppressed, it certainly seems possible to extend the range to several hundred meters or maybe even several kilometers.

The dimensions of the inverter are $6.5 \mathrm{~mm}$ in diameter and $23 \mathrm{~mm}$ in length, and it will prove simple to reduce the size. The entire actuator must be miniaturized and made lighter and must incorporate start, stop, and reverse functions. Future research will be directed toward these goals.

\section{References}

1) K. Tsuruta, T. Shibata, N. Mitsumoto, T. Sasaya and

M. Kawahara: Trans. IEE Jpn., 122, 2 (2002).

2) Y. Kondo and S. Yokota: Trans. J. Soc. Mec. Eng., 64, 617

(1998).

3) S. Yamamoto, K. Satou, K. Kikuchi and T. Matsu: Trans. J. Soc. Mec. Eng., 57, 540 (1991).

4) H. Saitou, K. Sato, K. Kudo and K. Sato: Trans. J. Soc. Mec. Eng., 66, 641 (2000).

5) H. Yaguchi: J. Magn. Soc. Jpn., 27, 4 (2003).

Received Oct. 4, 2004; Accepted Dec. 14, 2004 